\title{
EVALUATION OF OPERABILITY OF WWR-M REACTOR PRIMARY CIRCUIT PIPING WITH WELDED JOINT DEFECTS
}

\author{
O.V. MAKHNENKO, A.S. MILENIN and G.Yu. SAPRYKINA \\ E.O. Paton Electric Welding Institute, NASU \\ 11 Bozhenko Str., 03680, Kiev, Ukraine. E-mail: office@paton.kiev.ua
}

\begin{abstract}
Evaluation of load-carrying capacity of critical welded piping elements based on the results of technical diagnostics of their state is an important stage of a package of measures to confirm their operability and remaining safe operating life. In particular, in the case of detection of various defects of material discontinuity, it is necessary to perform static strength analysis of the piping and analysis of its strength factor correspondence to design requirements. If it is confirmed that the detected defects only slightly lower the piping load-carrying capacity, it can be allowed to operate in precised modes of force and corrosion impact. It is proposed to apply ductile fracture criterion based on multidimensional finite-element analysis of elastoplastic strain development. Admissibility of crack-like defects is substantiated by brittle-ductile fracture criteria. The case of an aluminium piping element of WWR-M research reactor primary circuit with detected multiple discontinuities of the weld (gas pores, nonmetallic inclusions) was used to show the sequence and main principles of analysis of defective piping load-carrying capacity. Community of the proposed methodological approaches allows their application at confirmation of operability of critical piping and pressure vessels from aluminium alloys and high-strength steels. 14 Ref., 1 Table, 7 Figures.
\end{abstract}

Key words: aluminium piping, defect admissibility, mathematical modeling, brittle-ductile fracture, stress strain state, numerical evaluation, load-carrying capacity

Radiographic testing of circumferential welded joints, performed after mounting primary circuit piping in WWR-M research reactor, revealed metal discontinuities in the form of pores and oxide film inclusions. Dimensions of individual discontinuities exceed the admissible limits according to currently valid rules and norms [1]. Normative documents [1,2] specify the possible deviations from the requirements. These deviations are documented by the joint decision of the design organization, manufacturing plant, etc. Then, they are coordinated with the head materials science organization, customer or operator.

In order to substantiate the operability without repairing the rectilinear sections of piping with discontinuities detected in circumferential welded joint zone, a computational study of the above discontinuity behaviour at working pressure in operation and at hydro-testing was performed.

Computational evaluation of stress-strain state in welded joint zone. Evaluation of nominal wall thickness in linear part of piping $\left(D_{a}=\right.$ $=370 \mathrm{~mm}, S=10 \mathrm{~mm}$ ) from aluminium alloy AMg3 in operation and at hydro-testing was performed in keeping with the normative document [3].

(C) O.V. MAKHNENKO, A.S. MILENIN and G.Yu. SAPRYKINA, 2015
Nominal wall thickness of the linear part in operation ( $p \leq 0.15 \mathrm{MPa}, T=55{ }^{\circ} \mathrm{C}$ ) is equal to $S_{R}=0.60 \mathrm{~mm}$, and at hydraulic testing ( $p=$ $\left.=0.32 \mathrm{MPa}, T=20{ }^{\circ} \mathrm{C}\right)-S_{R}=1.26 \mathrm{~mm}$.

Considering that the piping is designed for operation with distilled water at $T=55{ }^{\circ} \mathrm{C}$ and AMg3 alloy is corrosion-resistant, we can assume that $c=0.5 \mathrm{~mm}$ ( $c$ is the addition to wall thickness, allowing for its thinning because of corrosion over 50 years of operation).

Actual thickness of piping walls is more than 7 times greater than the nominal thickness, satisfying the static strength condition for the range of working and test pressures $(0.15-0.32 \mathrm{MPa})$.

Stress-strain state in the zone of piping butt welded joint is determined taking into account the following main components:

- working stresses from operating or test internal pressure; and

- residual stresses related to manufacturing or subsequent repair technology (multipass welding, possible local heat treatment in high tempering mode).

Calculation of stresses in the walls of piping linear part induced by working pressure in stationary temperature mode under normal operation conditions and by pressure at hydro-testing was performed allowing for the assumption of the piping geometrical and structural homogeneity [3]: $\sigma_{\beta \beta}=\left(p D_{a}\right) / 2 S$ are the circumferential and $\sigma_{z z}=\left(p D_{a}\right) / 4 S$ are the axial stresses. Cir- 


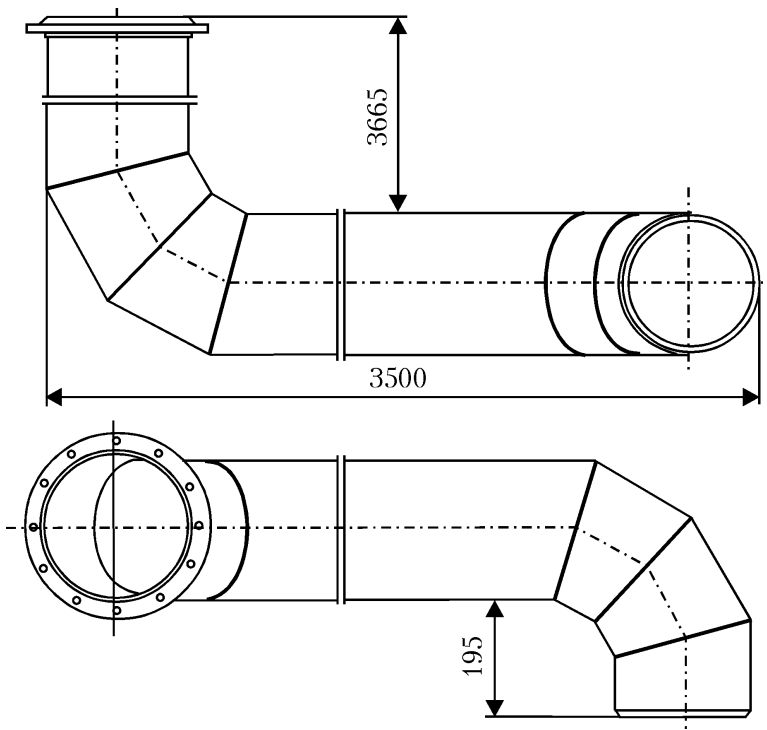

Figure 1. Schematic of piping from aluminium alloy AMg3 of WWR-M research reactor primary circuit

cumferential and axial components of stresses from working pressure are uniformly distributed across the piping thickness in its linear part. At working pressure $p=0.15 \mathrm{MPa}$ stresses in the wall are equal to $\sigma_{\beta \beta}=2.8 \mathrm{MPa}$ and $\sigma_{z z}=$ $=1.4 \mathrm{MPa}$, and at $p=0.32 \mathrm{MPa}$ stresses in the
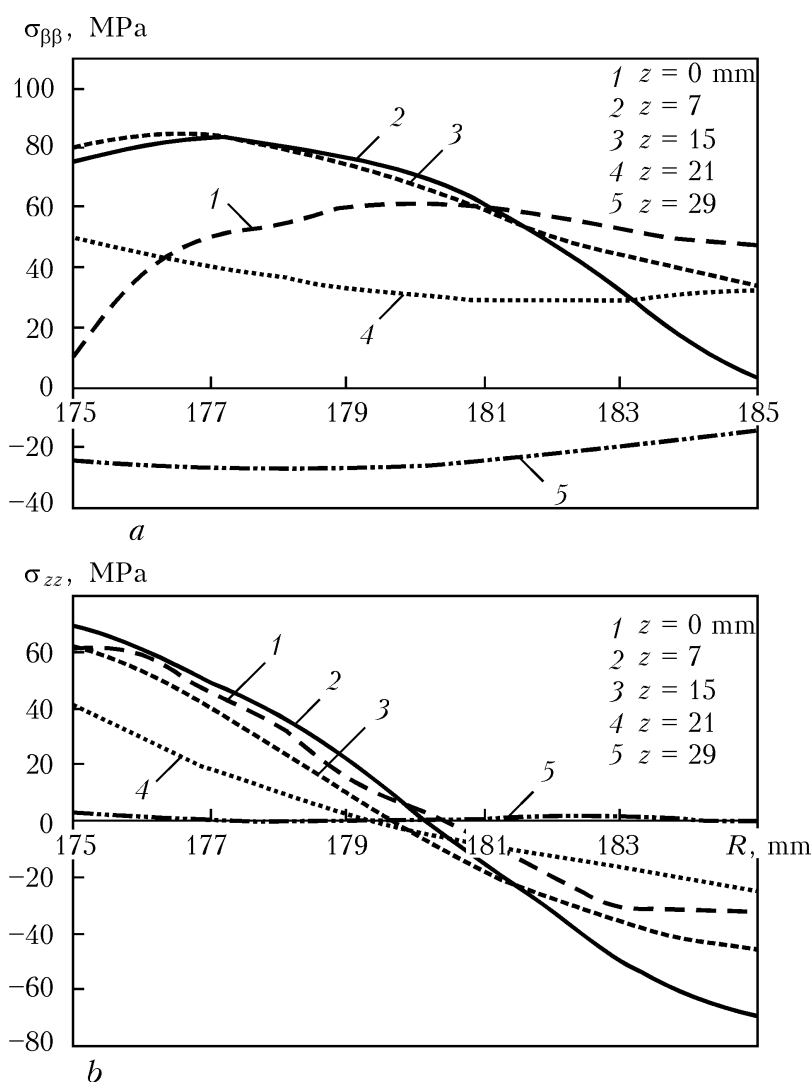

Figure 2. Distribution of residual stresses across the wall thickness in the zone of butt welded joint of piping $\left(D_{a}=\right.$ $=370 \mathrm{~mm}, S=10 \mathrm{~mm} ; R-$ pipe radius) from aluminium alloy AMg3 at different distances in the axial direction $z$ from welded joint center: $a-$ circumferential component $\sigma_{\beta \beta} ; b-$ axial component $\sigma_{z z}$ wall are equal to $\sigma_{\beta \beta}=5.9$ and $\sigma_{z z}=3.0 \mathrm{MPa}$, respectively.

Each of the two piping bends (Figure 1) was made by welding and consists of two sectors, connected to each other and to piping linear parts by three circumferential welded joints. To determine the peculiarities of stress distribution in welded joint zone, calculations were performed using a finite-element model of the bend in the case of internal pressure application. Results of calculation of circumferential and axial stress components in the piping bend zone from internal pressure showed that at $p=0.15 \mathrm{MPa}$ maximum tensile circumferential and axial stresses in the wall are determined on the external surface of the bend inner part (radius) and their value reaches 4.5 $\mathrm{MPa}$.

On the internal surface maximum tensile circumferential stresses are lower - up to $\sigma_{\beta \beta}=$ $=3.0 \mathrm{MPa}$, and axial stresses are up to $\sigma_{z z}=$ $=2.1 \mathrm{MPa}$. At $p=0.32 \mathrm{MPa}$ maximum tensile circumferential and axial stresses in the wall on the external surface of the bend inner part (radius) reach 9.6 $\mathrm{MPa}$. On the internal surface maximum tensile circumferential stresses $\sigma_{\beta \beta}$ reach $6.4 \mathrm{MPa}$, and axial stresses are up to $\sigma_{z z}=$ $=4.5 \mathrm{MPa}$. Thus, increase of stresses (maximum by $60 \%$ ) in the piping bend wall from internal pressure is of a local nature. Here, on the bend internal surface maximum stresses exceed those in the piping linear part by $10 \%$.

Distribution of residual welding stresses was calculated using FEM numerical procedure and computer program, included into the Weldpredictions system, developed at PWI [4, 5] and validated during performance of various studies [6]. Calculations showed that with the used technology of multipass welding of piping butt joints residual stressed state is characterized by quite high (on the level of AMg3 material yield point) circumferential $\sigma_{\beta \beta}$ and axial $\sigma_{z z}$ stresses on the wall internal surface (Figure 2).

In further calculations distribution of residual stresses and strains from internal pressure for circumferential welded joints in the piping bend part was assumed to be the same as for welded joints in the linear part, as welding was performed by the same technology, and $30^{\circ}$ angle of the sector (of the bend in the welded joint zone) is relatively small, and local increase of stresses from internal pressure in the bend part by 1.73.7 $\mathrm{MPa}$ (by $0.3-0.5 \mathrm{MPa}$ on the internal surface), compared to residual stresses (up to $80 \mathrm{MPa}$ ) can be ignored.

Numerical evaluation of load-carrying capacity of welded aluminium piping at internal 
pressure, allowing for the known degree of weld damage (pores formed in welding). Structure limiting state at static loading by internal pressure was described by limit hydrostatic pressure right up to initiation and development of ductile fracture processes in the area of geometrical and physical concentrators. It was believed that the structure state is inadmissible (limiting pressure has been reached) in the case of appearance of ductile fracture micropores, due to plastic flowing of metal.

In this work analysis of the stress-strain state of a welded structure in terms of ductile fracture was performed on the basis of a numerical solution of the problem of nonstationary thermoplasticity by tracing the elastoplastic strains from the moment of the start of multipass welding right up to complete cooling of the structure and at subsequent loading up to the limiting state within the finite-element model. Relation between stresses and strains was determined by Hooke's law and associated plastic flow rule, taking into account the postulates of complete Gurson-Tvergaard-Needleman model, proceeding from the following relationships [7]:

$$
\begin{gathered}
\Delta \varepsilon_{i j}=\psi\left(\sigma_{i j}-\delta_{i j} \sigma_{m}\right)+ \\
+\delta_{i j}\left(K \sigma_{m}+\Delta \varepsilon_{m}+\Delta f / 3\right)- \\
-\frac{1}{2 G}\left(\sigma_{i j}-\delta_{i j} \sigma_{m}\right)^{*}+\left(K \sigma_{m}\right)^{*},
\end{gathered}
$$

where $f$ is the volume concentration of ductile fracture micropores; $K=(1-2 v) / E ; G=$ $=E /(2(1+v)) ; E$ is the Young's modulus; $v$ is the Poisson's ratio; $\psi$ is the function of material state; determined by plastic flow condition in keeping with Mises criterion, additionally allowing for decrease of finite element load-carrying net-section as a result of formation of a discontinuity within Gurson-Tvergaard model:

$$
\begin{gathered}
\psi=\frac{1}{2 G,} \text { if } \sigma_{i}<\sigma_{s}=\sigma_{\mathrm{y}} \times \\
\times \sqrt{1+\left(q_{3} f^{*}\right)^{2}-2 q_{1} f^{*} \cosh \left(q_{2} \frac{3 \sigma_{m}}{2 \sigma_{\mathrm{y}}}\right)} \\
\psi>\frac{1}{2 G} \text { if } \sigma_{i}=\sigma_{s},
\end{gathered}
$$

where $q_{1}=1.5, q_{2}=1, q_{3}=1.5$ are the constants; $\sigma_{m}$ are the membrane stresses; $f^{*}$ is the equivalent volume concentration of pores allowing for their interaction in the finite element.

Magnitude of pore equivalent concentration is determined from the following relationship [8]:

$$
f^{*}=\left\{\begin{array}{l}
f, \text { if } f \leq f_{c}, \\
f_{c}=\frac{f_{u}^{*}-f_{c}}{f_{F}-f_{c}}\left(f-f_{c}\right), \text { if } f>f_{c},
\end{array}\right.
$$

where $f_{c}$ is the critical value of discontinuity concentration, below which the individual pores do not interact, it is taken to be $0.15 ; f_{F}$ is the pore concentration, at which finite element fracture takes place; $f_{u}^{*}=1 / q_{1}$.

It is assumed that pore initiation in the area of structural defects and discontinuities (socalled primary pores) is associated with an essential development of plastic strains and can be described using Odqvist parameter [8]

$$
\kappa=\int d \varepsilon_{i}^{p},
$$

where $d \varepsilon_{i}^{p}=\frac{\sqrt{2}}{3} \sqrt{d \varepsilon_{i j}^{p} d \varepsilon_{i j}^{p}} ; d \varepsilon_{i j}^{p}$ are the components of the tensor of plastic strain increment.

Accordingly, a condition of pore initiation in isothermal case is the current value of Odqvist parameter exceeding critical value $\kappa_{c}$.

Growth of initiating pores depends on the stress state rigidity and intensity of metal plastic strains and is described by Rice-Tracey law, namely [8]:

$$
d R=R_{0} K_{1} \exp \left(K_{2} \frac{\sigma_{m}}{\sigma_{i}}\right) d \varepsilon_{i}^{p},
$$

where $R, R_{0}$ are the current and initial pore radius; $\sigma_{m}=\left(\sigma_{x x}+\sigma_{y y}+\sigma_{z z}\right) / 3$ is the membrane stress; $\sigma_{i}=\sqrt{\left(\sigma_{i j} \sigma_{i j}\right) / 2}$ is the stress intensity; $\sigma_{m} / \sigma_{i}$ is the stressed state rigidity parameter; $K_{1}=0.28, K_{2}=1.5$ are the constants.

Figure 3 shows the results of technical diagnostics (roentgenoscopy) of welds and the most hazardous clusters of defects of gas pore type, the influence of which on piping load-carrying capacity was studied within the above procedure. Proceeding from computational results, data are given on limiting pressure for defect-free piping and piping with defects (the Table). Limiting pressure in this case does not allow for the system of safety factors specified for the given structure, but is a characteristic of the structure limiting state in the case of static force impact from internal pressure. The above-mentioned gas pores in the weld lower the piping limiting pressure by $15-23 \%$ and are admissible for piping static conditions only in the case of the respective excess structure safety factor used in design, as well as guaranteed absence of through-thickness pore groups (leaks, microleaks).

Determination of admissibility of discontinuities in the form of coarse inclusions in the 


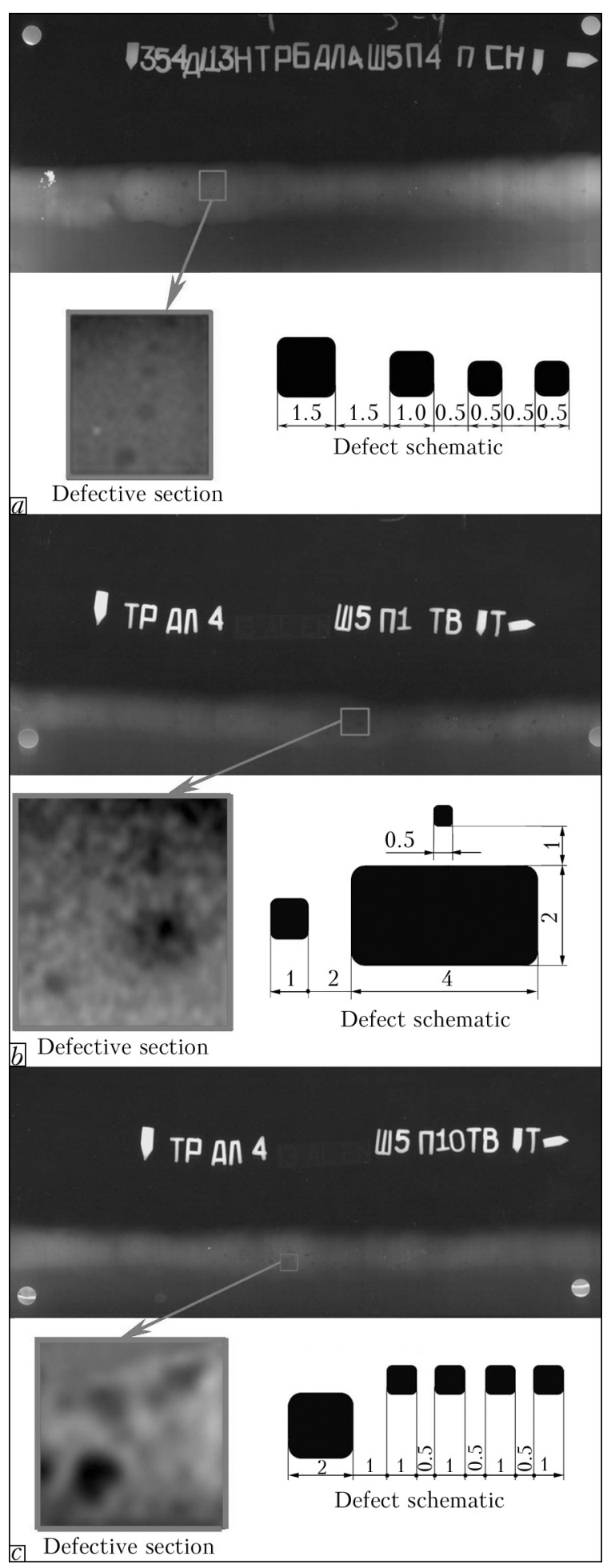

Figure 3. Examples of detected defects and their schematic representation: $a-$ 354AI13NTRBAL4Sh5P4PSN; $b-$ TRAL4Sh5P1TVT; $c-$ TRAL4Sh5P10TV film (see the Table)

zone of circumferential welded joint. Discontinuities in the form of coarse inclusions detected in the zone of circumferential welded joint of this piping, at computational evaluation of their admissibility in service and at hydro-testing, can conservatively be classified as crack-like defects. As inclusions can have different location relative
Results of limiting pressure calculation

\begin{tabular}{|c|l|c||}
\hline $\begin{array}{c}\text { Sample } \\
\text { number }\end{array}$ & \multicolumn{1}{|c|}{ Weld metal state } & $\begin{array}{c}\text { Limiting } \\
\text { pressure, MPa }\end{array}$ \\
\hline 1 & Defect-free metal & 4.9 \\
\hline 2 & $\begin{array}{l}\text { Weld metal with a defect group } \\
\text { (see Figure 3, } a \text { ) }\end{array}$ & 4.2 \\
\hline 3 & The same (see Figure 3, b) & 3.9 \\
\hline 4 & The same (see Figure 3,c) & 3.8 \\
\hline
\end{tabular}

to the pipe external or internal surface, conservative evaluation of their admissibility required considering the most critical case of such a defect, namely a semi-elliptical crack, reaching the internal surface, where welding induces the highest residual tensile stresses. A semi-elliptical crack, simulating the considered discontinuity, is characterized by $a$ (depth) and $2 c$ (length along the surface) (Figure 4). Stress intensity factors $K_{\mathrm{I}}$ in points $D$ and $G$ of the considered semi-elliptical crack can be calculated in keeping with the recommendations [9-12] and taking into account the data on stress distribution across the thickness of piping butt welded joint.

Condition of spontaneous growth (disequilibrium) of such a crack can be determined on the base of R6 approach widely accepted in nuclear power engineering $[13,14]$. In keeping with this approach, crack equilibrium is not disturbed, if the following condition is satisfied (Figure 5):

$$
K_{r}=K_{1} / K_{\mathrm{I} C},
$$

where $K_{r}=K_{\mathrm{I}} / K_{\text {IC }}$ is the ratio of intensity of stresses $K_{\mathrm{I}}$ in the crack tip to critical value of this parameter $K_{\mathrm{I} C} ; L_{r}=\sigma_{\text {ref }} / \sigma_{\mathrm{y}}$ is the ratio of critical stress value $\sigma_{\text {ref }}$, corresponding to ingress of plastic instability for the considered defect, to material yield point $\sigma_{\mathrm{y}}$. Type of function $f_{1}\left(L_{r}\right)$ is found experimentally.

We assume the criterion of spontaneous brittle-ductile fracture by $[13,14]$ in the following form:

$$
\begin{gathered}
K_{r} n=\left[1-0.14\left(L_{r} n\right)^{2}\right]\left[0.3+0.7 \exp \left(-0.65 L_{r}^{6} n^{6}\right)\right] \\
\text { at } L_{r} \leq L_{r}^{\max }=\frac{\sigma_{\mathrm{y}}+\sigma_{\mathrm{t}}}{2 \sigma_{\mathrm{y}}} \\
K_{r}=0 \text { at } L_{r}>L_{r}^{\max }
\end{gathered}
$$

where $n$ is the sought value of the safety factor determining the ratio of limit loads to those applied for the specified fracture; $\sigma_{t}$ is the material ultimate tensile strength.

Criterion of spontaneous brittle-ductile fracture (7) was used to perform calculations for piping with crack-like defects, located on the internal surface of a butt welded joint (in the 


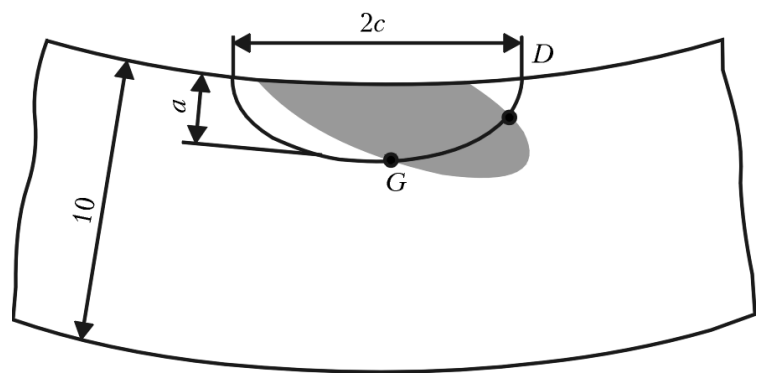

Figure 4. Schematic representation of discontinuity (coarse inclusion) on internal surface of piping butt welded joint by circumferential semi-elliptical crack

zone of maximum tensile stresses). Defect dimensions (depth $a$ and length $2 c$ of semi-elliptical crack) were varied within $10 \mathrm{~mm}$. As exact values of mechanical properties of aluminium piping weld metal are not available, the critical value of stress intensity factor $K_{\mathrm{IC}}$ was varied in the range from 13 up to $30 \mathrm{MPa} \cdot \mathrm{m}^{0.5}$.

Figures 6 and 7 show the results of calculation of safety factor values $n$ for spontaneous growth of the circumferential and axial crack, which is located on the internal surface of piping butt welded joint, depending on its dimensions $2 c$, $a / c=0.9, a / c=0.5$ and critical value $K_{\mathrm{I} C}=$ $=13$ and $30 \mathrm{MPa} \cdot \mathrm{m}^{0.5}$ of weld metal at working $(0.15 \mathrm{MPa})$ and test $(0.32 \mathrm{MPa})$ pressures. It is seen that for all the crack variants of up to $7.7 \times$

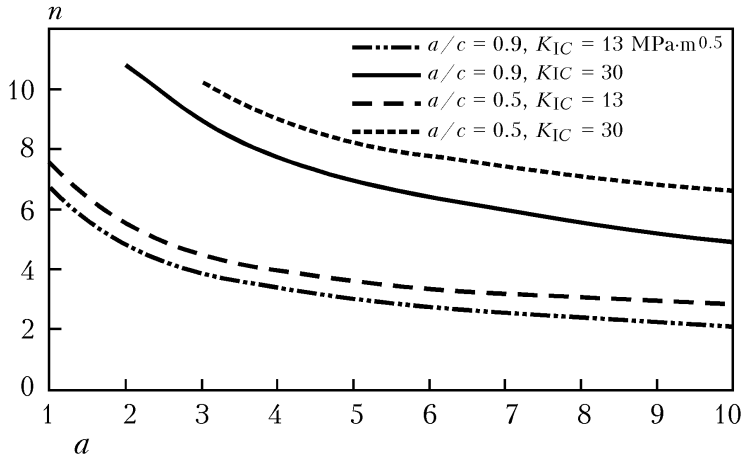

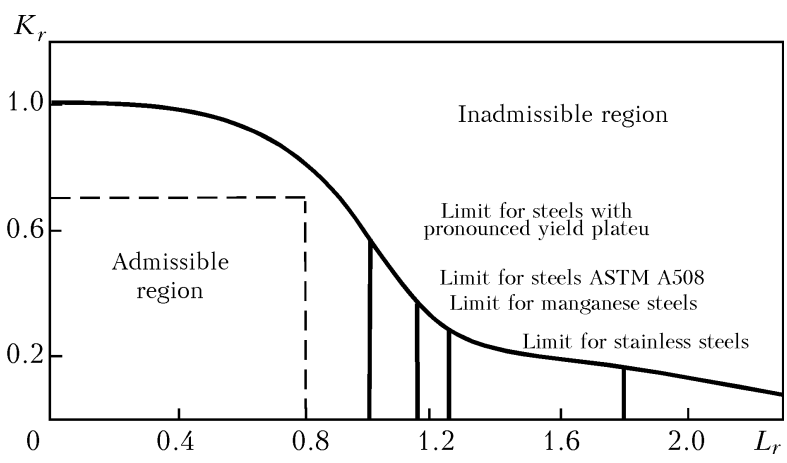

Figure 5. Limiting state diagrams $K_{r} \leq f_{1}\left(L_{r}\right)$ for structural steels of different types [13]

$\times 3.5 \mathrm{~mm}(a / c=0.9), 8 \times 2 \mathrm{~mm}(a / c=0.5)$ size and at assumption of sufficiently conservative fracture toughness value $K_{\mathrm{IC}}=13 \mathrm{MPa} \cdot \mathrm{m}^{0.5}$, safety factor values are higher than or are at the level of $n \geq 2$. Influence of the magnitude of working and test pressure on crack propagation is insignificant, as tensile residual stresses prevail on welded joint internal surface.

Thus, in the absence of corrosion and fatigue fracture mechanisms during operation of the considered piping there are no conditions for spontaneous growth of crack-like defects corresponding to coarse inclusions of up to $6.5 \times 1.5$ and $5.5 \times 3.5 \mathrm{~mm}$ size, found in the zone of circumferential welded joints.

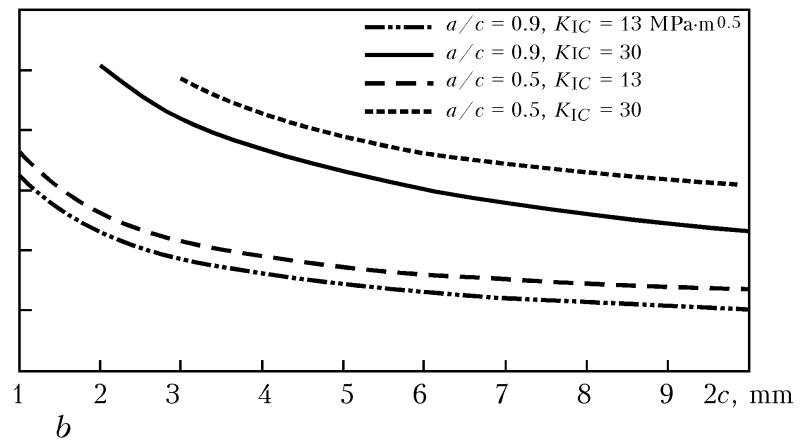

Figure 6. Dependence of safety factor $n$ for spontaneous growth of circumferential crack on its dimensions $2 c, a / c$ and critical $K_{\mathrm{I} C}$ of weld metal at $p_{\text {work }}=0.15(a)$ and $p_{\text {test }}=0.32(b) \mathrm{MPa}$
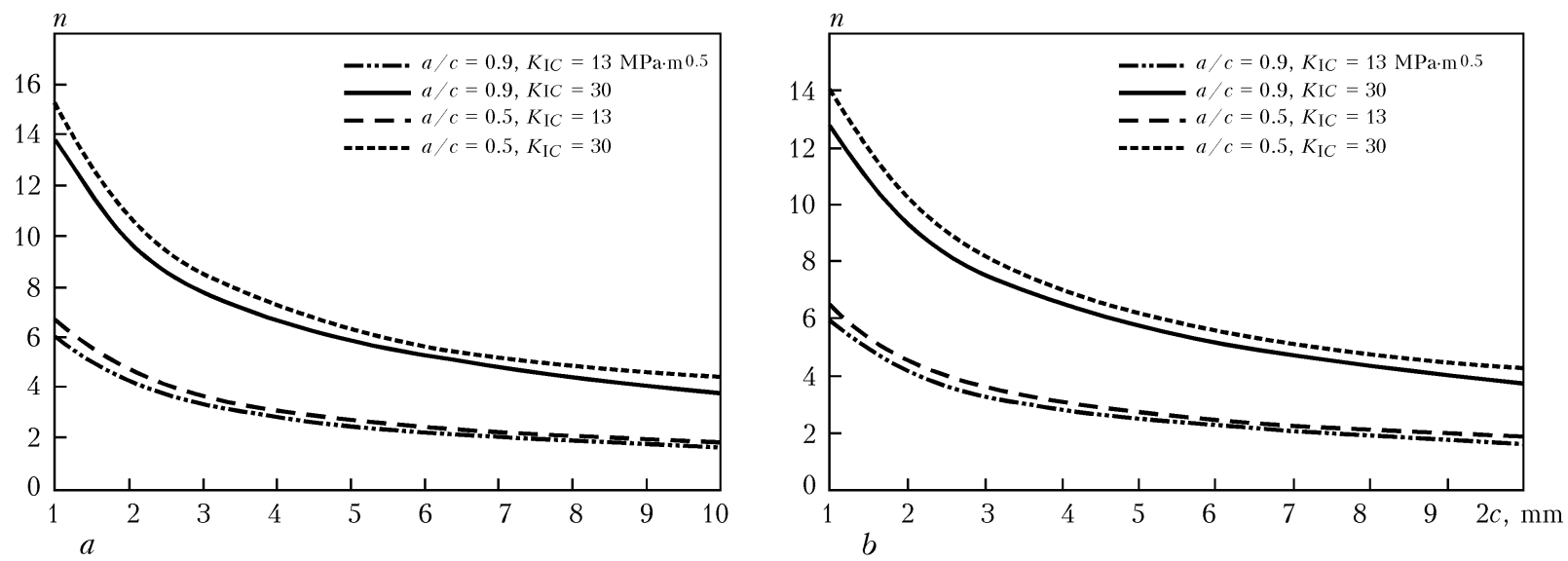

Figure 7. Dependence of safety factor $n$ for spontaneous growth of axial crack on its dimensions $2 c, a / c$ and critical $K_{\mathrm{IC}}$ of weld metal at $p_{\text {work }}=0.15(a)$ and $p_{\text {test }}=0.32(b) \mathrm{MPa}$ 


\section{Conclusions}

1. Computational study of behaviour of discontinuities in the form of pores and coarse inclusions, detected in the zone of circumferential welded joints, has been performed to substantiate the operability of WWR-M research reactor primary circuit piping (diameter $D_{a}=370 \mathrm{~mm}$, wall thickness $S=10 \mathrm{~mm}$ ) from aluminium alloy AMg3. Piping analysis for static strength showed that the actual thickness of piping walls is more than 7 times greater than the nominal thickness, satisfying the condition of static strength for working and test pressure range (0.15$0.32 \mathrm{MPa}$ ).

2. As shown by computation, the limiting state for the considered discontinuities is reached at internal pressure of $3.8-4.2 \mathrm{MPa}$, and in the defect-free section - at 4.9 MPa, i.e. lowering of welded piping ultimate load-carrying capacity is equal to approximately $15-23 \%$. For the range of working and test pressures $(0.15-0.32 \mathrm{MPa})$ the detected discontinuities in the form of gas pores in weld metal do not lower the considered piping load-carrying capacity.

3. Computation based on application of the criterion of spontaneous brittle-ductile fracture of piping with a crack (two-parametral criterion) showed that for inclusions (slag, tungsten or oxide films $)$ of up to $7.7 \times 3.5 \mathrm{~mm}(a / c=0.9)$, $8 \times 2 \mathrm{~mm}(a / c=0.5)$ size, even with the assumption of sufficiently conservative fracture toughness value $K_{\mathrm{IC}}=13 \mathrm{MPa} \cdot \mathrm{m}^{0.5}$ for welded joint metal, the calculated values of safety factor for spontaneous fracture are higher than $n>2$ both at working pressure of $0.15 \mathrm{MPa}$, and at test pressure of $0.32 \mathrm{MPa}$. Thus, in the absence of corrosion and fatigue fracture mechanisms in operation of the considered piping there are no conditions for spontaneous growth of crack-like defects (detected coarse inclusions) of up to $6.5 \times$ $\times 1.5$ and $5.5 \times 3.5 \mathrm{~mm}$ size in the zone of circumferential welded joints.
1. (1991) PNAE G-7-023-90: Equipment and pipelines of nuclear power plants. Aluminium alloy welded joints. Rules of control. Moscow: Energoatomizdat.

2. (1991) PNAE G-7-010-89: Equipment and pipelines of nuclear power plants. Welded joints and deposits. Rules of control. Moscow: Energoatomizdat.

3. (1987) PNAE G-7-002-86: Norms of strength analysis of equipment and piping of nuclear power plants. Moscow: Energoatomizdat.

4. Makhnenko, V.I. (1976) Calculation methods for the study of kinetics of welding stresses and strains. Kiev: Naukova Dumka.

5. Makhnenko, V.I., Velikoivanenko, E.A., Pochinok, V.E. et al. (1999) Numerical methods for the prediction of welding stresses and distortions. In: Welding and Surfacing Rev., Vol. 13. Amsterdam: Harwood Acad. Publ.

6. Makhnenko, V.I., Kasatkin, O.G., Velikoivanenko, E.A. et al. (1998) Calculated-experimental study of welding stresses in the zone of circumferential butts of pipelines DU-300 of ChNPP-3 KMPTs. In: Proc. of 5th Int. Conf. on Problems of Materials Science in Design, Manufacturing and Service of Nuclear Power Plant Equipment (Pushkin, Russia, 1998), Vol. 2, 53-66. St.-Petersburg: FGUP TsNII KM Prometej.

7. Makhnenko, V.I. (2013) Problems of examination of modern critical welded structures. The Paton Welding J., 5, 21-28.

8. Karzov, G.P., Margolin, B.Z., Shvetsova, V.A. (1993) Physical-mechanical modeling of fracture processes. St.-Petersburg: Politekhnika.

9. Procedural recommendations MR-125-01-90: Calculation of stress intensity factors and section weakening for defects in welded joints. Kiev.

10. Zvezdin, Yu.I., Rivkin, E.Yu., Vasilchenko, G.S. et al. (1990) Application of data of nondestructive testing in strength analysis. Tyazh. Mashinostroenie, 3, $12-14$.

11. Procedural recommendations MR-125-02-95: Rules for plotting design diagrams and determination of parameters of loading of structural elements with detected defects. Moscow: NPO TsNIITMASh.

12. Ovchinnikov, A.V., Zubchenko, A.S. (2010) Interpolation formulae of calculation of stress intensity factors for pressure vessels and pipelines. In: Problemy of nuclear science and engineering. Series Safety assurance of NPP. Issue 27: Reactor plants with WWER. Problems of strength, 58-70.

13. Milne, L., Ainsworth, R.A., Dowling A.R. et al. (1988) Assessment of the integrity of structure containing defects. Int. J. Pressure Vessels and Piping, 32(1-4), 3-104.

14. Makhnenko, V.I. (2006) Residual safe operating life of welded joints and sub-assemblies of modern structures. Kiev: Naukova Dumka. 